\title{
Performance of modified lightweight aggregate concrete after exposure to high temperatures
}

\section{Qianmin Ma}

Faculty of Civil Engineering and Mechanics, Kunming University of Science and Technology, Yunnan Key Laboratory of Disaster Reduction in Civil

Engineering, Kunming 650500, China (corresponding author: maqianmin666@163.com)

\section{Rongxin Guo}

Faculty of Civil Engineering and Mechanics, Kunming University of Science and Technology, Yunnan Key Laboratory of Disaster Reduction in Civil Engineering, Kunming, China

\section{Kecheng $\mathrm{He}$}

Traffic Bureau of Yangxi County, 89 Qiaoping No. 1 Road, Yangxi County, Yangjiang, China

Haiyun Du

China Railway Fifth Survey and Design Institute Group Co., Ltd,

9 Kangzhuang Road, Beijing, China

\author{
Zhiwei Lin \\ Faculty of Civil Engineering and Mechanics, Kunming University of \\ Science and Technology, Yunnan Key Laboratory of Disaster Reduction \\ in Civil Engineering, Kunming, China \\ Feng Yan \\ Faculty of Civil Engineering and Mechanics, Kunming University of \\ Science and Technology, Yunnan Key Laboratory of Disaster Reduction \\ in Civil Engineering, Kunming, China \\ Zhiman Zhao \\ Faculty of Civil Engineering and Mechanics, Kunming University of \\ Science and Technology, Yunnan Key Laboratory of Disaster Reduction \\ in Civil Engineering, Kunming, China \\ Yun Bai \\ Department of Civil, Environmental \& Geomatic Engineering, \\ University College London, London, UK
}

Lightweight expanded clay aggregates (ceramsites) were modified by coating a thin layer of alkali-activated fly ash binder. The modified aggregates were used to prepare concrete specimens, which were exposed to room and high temperatures. Spalling of the concrete specimens during heating and their mechanical properties after exposure were tested. Furthermore, hydration products of the alkali-activated fly ash and microscopic structures of the concrete specimens after exposure were also tested. In addition, in situ images of the concrete specimens were collected to demonstrate the formation and propagation of cracks in the specimens with increasing temperature. All the results were compared with results obtained for concretes prepared with normal lightweight aggregate and with crushed limestone. The results show that, unlike the reference concretes, nearly all the modified concrete specimens were intact, even at a temperature of $1200^{\circ} \mathrm{C}$, without spalling and retained good mechanical properties. Nepheline was detected in the alkali-activated fly ash after heating at $800^{\circ} \mathrm{C}$. Probably as a result of the strengthening of the alkali-activated fly ash coating, high temperatures induced cracks in the modified concrete that extended along the interfacial transition zone, but did not penetrate the interior of the aggregates.

\section{Notation}

E elastic modulus

$f_{\mathrm{cu}} \quad$ cube compressive strength

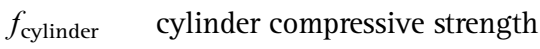

$f_{\mathrm{f}} \quad$ flexural strength

$f_{\mathrm{t}} \quad$ splitting tensile strength

$n \quad$ total number of specimens

$n_{\mathrm{sp}} \quad$ number of spalled specimens

$T_{\mathrm{sp}} \quad$ temperature at which spalling first occurred

\section{Subscripts}

$T \quad$ temperature

20 room temperature $\left({ }^{\circ} \mathrm{C}\right)$

\section{Introduction}

Lightweight aggregates, such as expanded clay (ceramsite), expanded perlite and pumice, are usually used to prepare lightweight aggregate concrete. One of the main applications of such concrete is in the construction of filler walls of high-rise buildings, owing to the advantage of its light weight. Fire is a tremendous threat for high-rise buildings, as frequently reported worldwide in recent years. High temperature is well known to cause serious damage to both the macroscopic and microscopic structures of concrete, leading to generalised mechanical decay of the concrete and even detrimental effects at the structural level, owing to concrete spalling (Choi et al., 2017; Gao et al., 2017; Ma et al., 2015, 2018). The deterioration of concrete at high temperature is mainly caused by damage to the binder or aggregates; their influences on the mechanical properties of concrete at high temperature have been reviewed previously (Ma et al., 2015).

Lightweight aggregates are normally formed by volcano eruption or incineration. As a result, they have low heat conductivity and exhibit a high resistance to heat. Therefore, concrete manufactured using such aggregates should deliver improved mechanical properties at high temperature, in comparison with concrete containing normal aggregates (Jiang et al., 2013; Sancak et al., 2008; Tanyildizi and Coskun, 2008; 
Turkmen and Findik, 2013; Yoon et al., 2015). Internationally established lightweight aggregates, such as Lytag (2017) and Leca (2017), which are mainly produced from power station ash and expanded clay, respectively, have also brought superior fire resistance to concretes containing them.

However, the occurrence of thermal spalling will extremely limit the resistance of concrete to high temperature (Ma et al., 2015). Thermal spalling of concrete is greatly sensitive to its moisture content (Ma et al., 2015). Jiang et al. (2013) point out that hightemperature-induced spalling did not occur when moisture content (calculated by using evaporative water content in a concrete specimen at a certain moment divided by that in the specimen just taken out from the standard curing room) in normal concrete is below $75 \%$, whilst this value for lightweight concrete was $25 \%$. This indicates that spalling of lightweight concrete at high temperature is much more sensitive than normal concrete to moisture content. It is known that the porosity of lightweight aggregates, and consequently the water absorption, is much higher than that of normal aggregates. Therefore, in practice, to minimise water absorption of lightweight aggregates and its effect on the workability and subsequent setting and hardening of the concrete produced, lightweight aggregates are usually presaturated before mixing. However, such treatment will bring extra water into the concrete to increase its moisture content, thus increasing the possibility of spalling at high temperature. Although the moisture in lightweight aggregates might evaporate into the atmosphere during concrete service, owing to their highly porous characteristics, lightweight aggregates would also heavily absorb moisture again to induce spalling of the concrete in a fire caused by gas or other fuel (Lindgard and Hammer 1998). This will extremely limit the super resistance of lightweight aggregate to heat. In many studies (Sancak et al., 2008; Tanyildizi and Coskun, 2008; Turkmen and Findik, 2013; Yoon et al., 2015), researchers did not follow the practical process of presaturating lightweight aggregates before concrete mixing. Jiang et al. (2013) dried lightweight concrete specimens at $100^{\circ} \mathrm{C}$ before exposing them to high temperature, which minimised spalling to a large extent. However, such pre-drying action is impossible in practice.

From this discussion, it can be seen that, owing to either the original moisture in lightweight aggregate concrete or its reabsorption in a fire, such concrete has a high probability of spalling at high temperature. Therefore, it is necessary to propose a method to modify lightweight aggregates to reduce their absorption, thus reducing the possibility of spalling of the concrete at high temperature.
Surface coating is considered to be a useful method to reduce absorption of water by lightweight aggregates, thus reducing the possibility of spalling of the concrete. In our previous investigation (Ma et al., 2018) and the study carried out by Bideci (2016), inorganic polymer compound material and cement + colemanite (a kind of boron mineral), respectively, were used to coat lightweight aggregates to reduce the frequency of spalling. In the former study, the frequency of spalling of lightweight aggregate concrete was reduced by decomposition of the coating material at a lower temperature to generate channels for vapour to escape. By contrast, the coating used in the latter study was applied to strengthen the lightweight aggregates, increasing the resistance of the concrete to high temperature. However, because spalling was not the main concern in the latter study, the experimental design did not consider related procedures. However, probably because Portland cement-based material was used for coating, when the temperature was increased to $600^{\circ} \mathrm{C}$, very deep and wide cracks were still found at the surface of the concrete. Researchers (Guerrieri and Sanjayan, 2010; Ranjbar et al., 2014; Rashad and Zeedan, 2011; Thokchom et al., 2012; Zhang et al., 2015) have reported that alkali-activated fly ash has superior heat resistance because the high temperature simply provides a desirable environment for the activation. In this context, such a binder was selected in this study to coat lightweight aggregates, and the thermal spalling and mechanical properties of the concrete containing the coated aggregates after high-temperature exposure were investigated.

\section{Experimental programme}

In this paper, lightweight expanded clay aggregates (ceramsites) were precoated using alkali-activated fly ash. The modified ceramsites were used to produce lightweight fly ash aggregate concrete (FAAC). Thermal spalling and the mechanical properties of the concrete after exposure to high temperatures were studied. Furthermore, the formation of hydration products of the alkaliactivated fly ash and microscopic structures of the concrete with increasing temperature were also examined in order to understand the role of the alkali-activated fly ash. The macroscopic structure of the concrete was also observed in situ to examine the formation and propagation of cracks in the concrete. Normal ceramsite concrete (NCC) and crushed limestone concrete (CLC) specimens were also prepared as reference for comparison.

\section{Materials}

\section{Cement}

The cement used to manufacture the concrete specimens was slag Portland cement PSA $32 \cdot 5$, which conforms to Chinese

Table 1. Chemical compositions of cement and fly ash (\%)

\begin{tabular}{|c|c|c|c|c|c|c|c|}
\hline & $\mathrm{SiO}_{2}$ & $\mathrm{CaO}$ & $\mathrm{Al}_{2} \mathrm{O}_{3}$ & $\mathrm{Fe}_{2} \mathrm{O}_{3}$ & MgO & $\mathrm{SO}_{3}$ & Loss on ignition \\
\hline Cement & $17 \cdot 90$ & 54.03 & $5 \cdot 26$ & $3 \cdot 44$ & $1 \cdot 78$ & $1 \cdot 70$ & $4 \cdot 30$ \\
\hline Fly ash & $43 \cdot 60$ & $3 \cdot 14$ & 24.03 & 6.93 & $2 \cdot 44$ & 0.30 & $3 \cdot 75$ \\
\hline
\end{tabular}




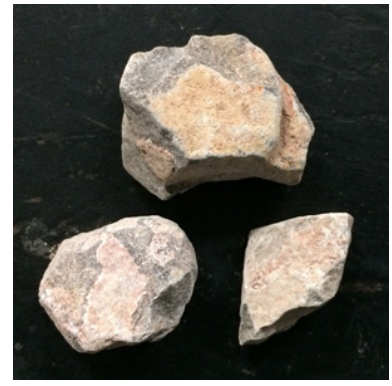

(a)

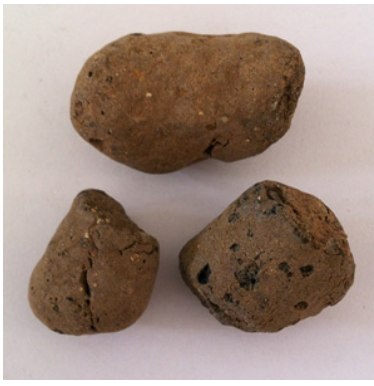

(b)

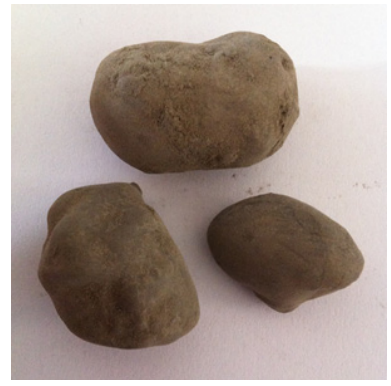

(c)

Figure 1. Appearance of the coarse aggregates: (a) limestone; (b) ceramsite; (c) modified ceramsite

national standard GB 175-2007 (SAC, 2007). Table 1 gives its chemical composition.

\section{Fine aggregates}

Fine aggregates were prepared using three parts of manufactured sand and two parts of mountain sand (by mass), whose fineness modulus, specific gravity and $1 \mathrm{~h}$ water absorption were $2 \cdot 54,2 \cdot 72$ and $2 \cdot 3 \%$, respectively.

\section{Coarse aggregates}

Normal ceramsites without modification were used to prepare NCC specimens; CLC specimens were manufactured using crushed limestone. The reason for using limestone to manufacture reference concrete was that, compared with siliceous aggregates, limestone with this kind of calcareous aggregate has a higher resistance to heat (Ma et al., 2015). The maximum size of both kinds of aggregate was $30 \mathrm{~mm}$, and they both had a good particle distribution. For the manufacture of FAAC specimens, ceramsites were precoated with alkali-activated fly ash before concrete mixing. A sodium hydroxide solution with a concentration of $8 \mathrm{~mol} / \mathrm{l}$ was mixed with the fly ash powder, where the ratio between the solution and the powder was $1 \cdot 2: 1$. When the alkali-activated fly ash slurry was ready, ceramsite particles were put into a proper amount of slurry for coating. After removing excess slurry from the surface of the particles with a sieve, the coated ceramsites were immediately dried in an oven at $80^{\circ} \mathrm{C}$ for $5 \mathrm{~h}$ (Guo et al., 2016). The chemical composition of the fly ash used is given in Table 1 . The appearances of all kinds of coarse aggregates are shown in Figure 1, and their properties are given in Table 2.

\section{Water}

Tap water was applied to mix and cure the concrete specimens.

\section{Preparation of specimens}

\section{Mix proportions}

As stated in the introduction, the main application of lightweight aggregate concrete is as non-bearing filler walls for highrise buildings. As a result, according to Chinese standard JGJ
Table 2. Properties of the coarse aggregates

\begin{tabular}{|lcc|} 
Aggregate & $\begin{array}{c}\text { Specific gravity (saturated } \\
\text { surface dry condition) }\end{array}$ & $\begin{array}{c}\mathbf{1} \text { h water } \\
\text { absorption: \% }\end{array}$ \\
\hline Limestone & 2.38 & 0.5 \\
Ceramsite & 0.82 & 14.5 \\
Modified ceramsite & 0.98 & 9.2 \\
\hline
\end{tabular}

51-2002 (SAC, 2002a), a strength class of LC10 was chosen as the target in this study. The same water-to-binder ratio, cement content and total volume of aggregates were used to manufacture NCC and FAAC specimens. The CLC specimens also used the same water-to-binder ratio and cement content. Chinese standards JGJ51-2002 (SAC, 2002a) and JGJ55-2011 (SAC, 2011) were used to formulate the mix design of lightweight aggregate concretes and CLC, respectively. Table 3 gives the mix proportions of the concrete mixes studied in detail.

\section{Preparation of specimens}

At each temperature, three specimens for each mix were cast for the following tests: (a) a cube compressive strength test with a specimen size of $100 \mathrm{~mm} \times 100 \mathrm{~mm} \times 100 \mathrm{~mm}$; (b) a splitting tensile strength test with a specimen size of $100 \mathrm{~mm} \times 100 \mathrm{~mm} \times 100 \mathrm{~mm}$; (c) a flexural strength test with a specimen size of $100 \mathrm{~mm} \times 100 \mathrm{~mm} \times 400 \mathrm{~mm}$; (d) stress-strain relationship, cylinder compressive strength and elastic modulus tests with a specimen size of $100 \mathrm{~mm} \times 100 \mathrm{~mm} \times 300 \mathrm{~mm}$.

Both the ceramsite particles with and without precoating were presaturated in water before casting. The water content formulated in the mix proportions (detailed in Table 3) did not include the water used for saturation.

After casting, the specimens were cured in moulds; the temperature was maintained at $20 \pm 2^{\circ} \mathrm{C}$ and relative humidity was controlled beyond $95 \%$. The specimens were unmoulded $1 \mathrm{~d}$ after casting, and then cured under the same conditions. The total curing duration was $28 \mathrm{~d}$. 
Table 3. Concrete mix proportions $\left(\mathrm{kg} / \mathrm{m}^{3}\right)$

\begin{tabular}{lcccr|} 
Concrete type & Cement & Water & Fine aggregates & Coarse aggregates \\
\hline CLC & 370 & 180 & 658 & 1222 \\
NCC & 370 & 180 & 693 & 317 \\
FAAC & 370 & 180 & 693 & 378
\end{tabular}

Table 4. Slump of the fresh concretes and mechanical properties of the hardened concretes at a curing age of $28 \mathrm{~d}$ (room temperature)

\begin{tabular}{lcccccc} 
Concrete type & Slump: $\mathbf{m m}$ & $\boldsymbol{f}_{\text {cu: }}: \mathbf{M P a}$ & $\boldsymbol{f}_{\text {cylinder: }}: \mathbf{M P a}$ & $\boldsymbol{f}_{\mathbf{t}}: \mathbf{M P a}$ & $\boldsymbol{f}_{\mathbf{f}}: \mathbf{M P a}$ & $\boldsymbol{E}: \mathbf{G P a}$ \\
CLC & 100 & $35 \cdot 1 \pm 1 \cdot 1$ & $29 \cdot 8 \pm 0 \cdot 9$ & $3 \cdot 26 \pm 0 \cdot 0$ & $4 \cdot 80 \pm 0 \cdot 3$ & $23 \cdot 3 \pm 0 \cdot 4$ \\
NCC & 80 & $14 \cdot 9 \pm 0 \cdot 9$ & $13 \cdot 3 \pm 0 \cdot 5$ & $1 \cdot 76 \pm 0 \cdot 1$ & $2 \cdot 50 \pm 0 \cdot 0$ & $15 \cdot 4 \pm 0 \cdot 3$ \\
FAAC & 80 & $15 \cdot 2 \pm 0 \cdot 2$ & $13 \cdot 9 \pm 0 \cdot 6$ & $1 \cdot 61 \pm 0 \cdot 2$ & $2 \cdot 50 \pm 0 \cdot 2$ & $14 \cdot 9 \pm 0 \cdot 8$ \\
\hline
\end{tabular}

\section{Heating regime}

An electric heating furnace was used in this study to heat the concrete specimens. The specimens were placed in the furnace in an unstressed condition. Ceramic cellular pads with very small section were used to support the specimens at the four corners, allowing all six surfaces of the specimens to be heated during temperature elevation. The temperature was elevated at a rate of $10^{\circ} \mathrm{C} / \mathrm{min}$ to $200,400,600,800,1000$ and $1200^{\circ} \mathrm{C}$, respectively. The temperatures were maintained constant for $3 \mathrm{~h}$ when the target temperature was achieved, so that a thermal steady state could be obtained in the specimens. After that, the furnace was switched off and the specimens were cooled down slowly in the furnace to room temperature.

\section{Tests}

\section{Slump}

A slump test was carried out on the fresh concretes following the specifications in Chinese standard GB/T 50080-2002 (SAC, 2002b); the results are presented in Table 4 .

\section{Mechanical properties}

After a curing duration of $28 \mathrm{~d}$, the concrete specimens were tested for their cube compressive strength $\left(f_{\text {cu }}\right)$, splitting tensile strength $\left(f_{\mathrm{t}}\right)$, flexural strength $\left(f_{\mathrm{f}}\right)$ and stress-strain relationship at room temperature and after the high-temperature heating. The cylinder compressive strength $\left(f_{\text {cylinder }}\right)$ and elastic modulus $(E)$ of the specimens can also be obtained from the results of the stress-strain relationship test. All these tests were carried out by following the specifications in Chinese standard GB/T 50081-2002 (SAC, 2002c). Table 4 gives the strengths and the elastic moduli of the specimens at room temperature.

\section{Spalling}

In the process of heating, if sounds of spalling were heard, the corresponding temperature was recorded. When the specimens had cooled down, they were removed from the furnace and the spalling mode was recorded for each spalled specimen. Furthermore, the quantity of the specimens spalled was confirmed and the spalling frequency was calculated.

\section{Hydration products of alkali-activated fly ash}

To understand the role of alkali-activated fly ash in FAAC, X-ray diffraction techniques were applied to such a system at room temperature and after heating, with an attempt to determine the evolution of the hydration products of the system with increasing temperature. Alkali-activated fly ash paste was prepared with the same mix proportion and procedure as that used for the ceramsite coating. The same curing regime used for the concrete was used to cure the paste for $28 \mathrm{~d}$. Temperatures of $400^{\circ} \mathrm{C}, 800^{\circ} \mathrm{C}$ and $1200^{\circ} \mathrm{C}$ were selected for heating, where the same heating regime as that used for concrete specimens was applied to the paste specimens. The heated specimens at the different temperatures and the specimen kept at room temperature were ground into powder (passing through a $0.08 \mathrm{~mm}$ sieve), and the powder samples were immediately analysed using X-ray diffraction.

\section{Microscopic structure}

When the concrete specimens were crushed for the mechanical property tests at room temperature and after heating, a number of small and thin fragments, which included both cement matrix and aggregates, were collected. Absolute ethanol was then used to soak the fragments for $3 \mathrm{~d}$ to terminate any possible hydration, After drying in a vacuum drying dish, scanning electron microscopy was used to observe the microscopic structure of the fragments.

\section{In situ macroscopic structure}

A concrete cube of size $100 \mathrm{~mm} \times 100 \mathrm{~mm} \times 100 \mathrm{~mm}$ was manufactured for each mix for in situ macroscopic structure observation. After a curing duration of $28 \mathrm{~d}$ under the same regime used for the other concrete specimens, the surfaces of the cube were cut off and a prism of size $40 \mathrm{~mm} \times 40 \mathrm{~mm} \times 80 \mathrm{~mm}$ was prepared, which was polished. Furthermore, the prism specimen was put into an electrical furnace with a visible window. The temperature in the furnace was elevated at a rate of $50^{\circ} \mathrm{C} / \mathrm{min}$ from room temperature to an ultimate temperature of $800^{\circ} \mathrm{C}$. During the temperature elevation, in situ images of the specimens were collected at 20, 100, 200, 300, 400, 500, 600, 700 and $800^{\circ} \mathrm{C}$, using a charged-couple device high-temperature in situ digital image collection system. Because the prism 
Table 5. Spalling frequency of concrete specimens at high temperatures

\begin{tabular}{|c|c|c|c|c|c|c|c|c|c|c|}
\hline \multirow[b]{2}{*}{ Concrete type } & \multirow[b]{2}{*}{ Temperature: ${ }^{\circ} \mathrm{C}$} & \multicolumn{2}{|c|}{$\begin{array}{c}f_{\mathrm{cu}} \text { test } \\
(100 \times 100 \times 100 \mathrm{~mm})\end{array}$} & & \multicolumn{2}{|c|}{$\begin{array}{c}f_{\mathrm{t}} \text { test } \\
(100 \times 100 \times 100 \mathrm{~mm})\end{array}$} & \multicolumn{2}{|c|}{$\begin{array}{c}\text { Stress-strain } \\
\text { relationship test } \\
(100 \times 100 \times 300 \mathrm{~mm})\end{array}$} & \multicolumn{2}{|c|}{$\begin{array}{c}f_{\mathrm{f}} \text { test } \\
(100 \times 100 \times 400 \mathrm{~mm})\end{array}$} \\
\hline & & $n_{\mathrm{sp}} / n$ & $T_{\mathrm{sp}}:{ }^{\circ} \mathrm{C}$ & & $n_{\mathrm{sp}} / n$ & $T_{\mathrm{sp}}:{ }^{\circ} \mathrm{C}$ & $n_{\mathrm{sp}} / n$ & $T_{\mathrm{sp}}:{ }^{\circ} \mathrm{C}$ & $n_{\mathrm{sp}} / n$ & $T_{\text {sp }}:{ }^{\circ} \mathrm{C}$ \\
\hline \multirow{9}{*}{ CLC } & 20 & - & - & & - & - & - & - & - & - \\
\hline & 200 & $0 / 3$ & - & & $0 / 3$ & - & $0 / 3$ & - & $0 / 3$ & - \\
\hline & 400 & $0 / 3$ & - & & $0 / 3$ & - & $0 / 3$ & - & $0 / 3$ & - \\
\hline & 600 & $1 / 3$ & 488 & & $1 / 3$ & 492 & $1 / 3$ & 547 & $3 / 3$ & $502 / 510 / 508$ \\
\hline & 800 & $1 / 3$ & 486 & & $1 / 3$ & 495 & $2 / 3$ & $540 / 542$ & $3 / 3$ & $498 / 513 / 511$ \\
\hline & 1000 & $0 / 3$ & - & & $0 / 3$ & - & $2 / 3$ & $510 / 542$ & $3 / 3$ & $520 / 542 / 518$ \\
\hline & 1200 & $0 / 3$ & - & & $0 / 3$ & - & $3 / 3$ & $533 / 540 / 516$ & $3 / 3$ & $492 / 517 / 495$ \\
\hline & Spalling frequency: \% & & & $11 \cdot 1$ & & & & $44 \cdot 4$ & & $66 \cdot 7$ \\
\hline & Average $T_{\text {sp }}:{ }^{\circ} \mathrm{C}$ & & & 490 & & & & 534 & & 510 \\
\hline \multirow[t]{9}{*}{ NCC } & 20 & - & - & & - & - & - & - & - & - \\
\hline & 200 & $0 / 3$ & - & & $0 / 3$ & - & $0 / 3$ & - & $0 / 3$ & - \\
\hline & 400 & $0 / 3$ & - & & $0 / 3$ & - & $1 / 3$ & 387 & $1 / 3$ & 387 \\
\hline & 600 & $3 / 3$ & $416 / 453 / 456$ & & $3 / 3$ & $397 / 450 / 461$ & $3 / 3$ & $396 / 407 / 412$ & $3 / 3$ & $412 / 423 / 417$ \\
\hline & 800 & $3 / 3$ & $435 / 444 / 498$ & & $3 / 3$ & $432 / 451 / 456$ & $3 / 3$ & 402/388/392 & $3 / 3$ & $407 / 386 / 425$ \\
\hline & 1000 & $3 / 3$ & $408 / 452 / 460$ & & $3 / 3$ & $421 / 434 / 451$ & $3 / 3$ & $432 / 410 / 391$ & $3 / 3$ & $445 / 412 / 426$ \\
\hline & 1200 & $3 / 3$ & $412 / 440 / 462$ & & $3 / 3$ & $441 / 462 / 461$ & $3 / 3$ & $398 / 421 / 395$ & $3 / 3$ & $392 / 436 / 414$ \\
\hline & Spalling frequency: \% & & & $66 \cdot 7$ & & & & $72 \cdot 2$ & & $72 \cdot 2$ \\
\hline & Average $T_{\text {sp }}:{ }^{\circ} \mathrm{C}$ & & & 444 & & & & 402 & & 414 \\
\hline \multirow[t]{9}{*}{ FAAC } & 20 & - & - & & - & - & - & - & - & - \\
\hline & 200 & $0 / 3$ & - & & $0 / 3$ & - & $0 / 3$ & - & $0 / 3$ & - \\
\hline & 400 & $0 / 3$ & - & & $0 / 3$ & - & $0 / 3$ & - & $0 / 3$ & - \\
\hline & 600 & $0 / 3$ & - & & $0 / 3$ & - & $0 / 3$ & - & $0 / 3$ & - \\
\hline & 800 & $0 / 3$ & - & & $0 / 3$ & - & $1 / 3$ & 472 & $0 / 3$ & - \\
\hline & 1000 & $0 / 3$ & - & & $0 / 3$ & - & $1 / 3$ & 437 & $0 / 3$ & - \\
\hline & 1200 & $0 / 3$ & - & & $0 / 3$ & - & $0 / 3$ & - & $0 / 3$ & - \\
\hline & Spalling frequency: \% & & & $0 \cdot 0$ & & & & $11 \cdot 1$ & & 0.0 \\
\hline & Average $T_{\mathrm{sp}}:{ }^{\circ} \mathrm{C}$ & & & - & & & & 454 & & - \\
\hline
\end{tabular}

Note: Spalling frequency is calculated by using the number of the specimens spalled divided by the total number of the specimens exposed to a temperature $\geq 200^{\circ} \mathrm{C}$ 

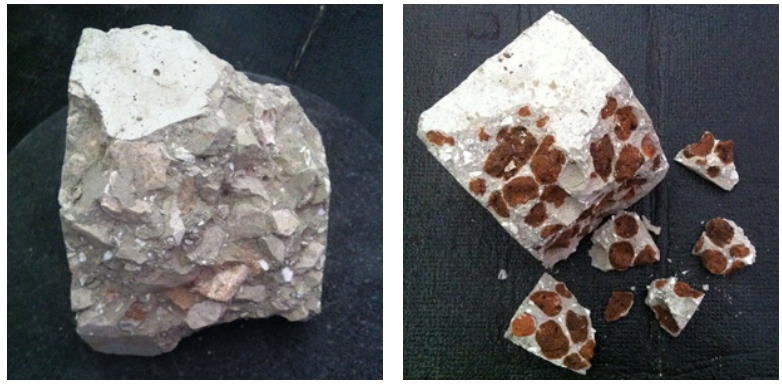

(a)
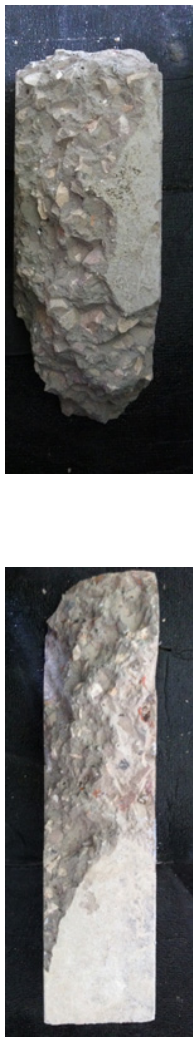

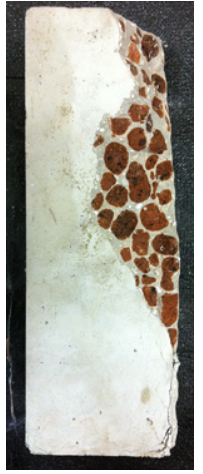

(b)

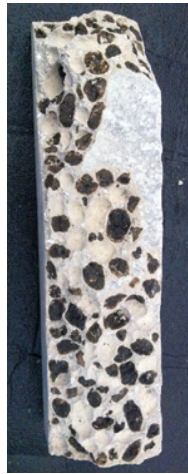

(c)
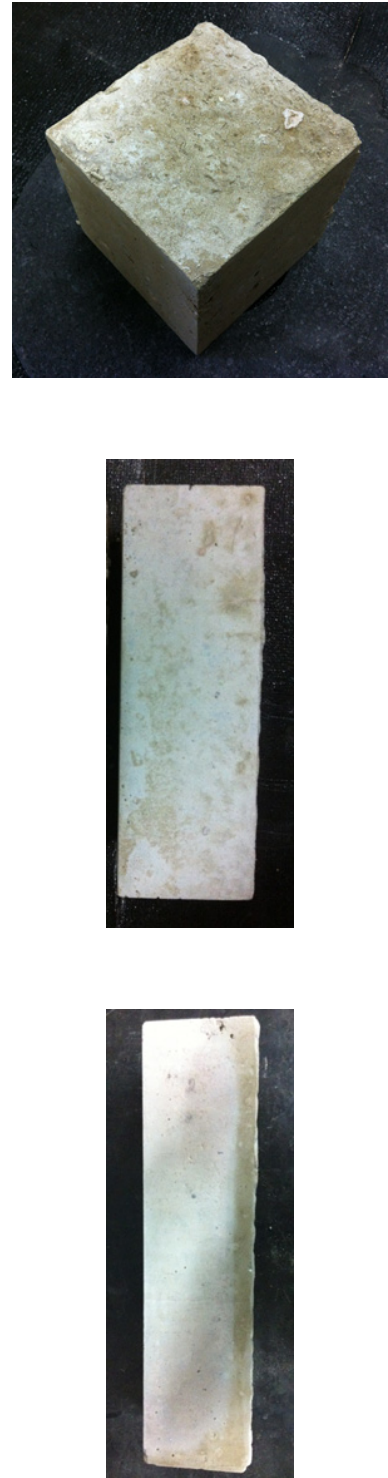

Figure 2. Appearance of the concrete specimens after heating to $1200^{\circ} \mathrm{C}$ (from left to right: $C L C, N C C, F A A C$ ): (a) specimens of size $100 \mathrm{~mm} \times 100 \mathrm{~mm} \times 100 \mathrm{~mm}$; (b) specimens of size $100 \mathrm{~mm} \times 100 \mathrm{~mm} \times 300 \mathrm{~mm}$; (c) specimens of size $100 \mathrm{~mm} \times 100 \mathrm{~mm} \times 400 \mathrm{~mm}$

specimens were relatively small and cut surfaces were used for observation, moisture in the specimens could easily escape into the atmosphere. In this context, thermal spalling was not considered to occur in such prism specimens, and the purpose of the in situ macroscopic structure observation was simply to evaluate the formation and propagation of cracks in the specimens with increasing temperature.

\section{Results and discussion}

\section{Spalling}

Table 5 details the number of spalled concrete specimens $\left(n_{\mathrm{sp}}\right)$ at each temperature and the temperature when spalling first occurred $\left(T_{\mathrm{sp}}\right)$. Furthermore, a spalling frequency was calculated for specimens of different sizes, and is also reported in Table 5. Compared with CLC, NCC specimens spalled severely and the spalling started at a lower temperature. As given in Table 2, the $1 \mathrm{~h}$ water absorption of ceramsite was $14 \cdot 5 \%$ which was much higher than that of limestone, of $0 \cdot 5 \%$. As a result, the water content in NCC should be higher than that of CLC. Owing to the vapour pressure (Consolazio et al., 1998), thermal spalling was much more likely to occur for the NCC specimens when they were heated.

However, after the modification, the spalling frequency of FAAC was reduced remarkably, no matter what the size of the specimens. As reported in Table 2, alkali-activated fly ash coating has reduced the water absorption of the ceramsite. 
This could be one of the reasons why the spalling frequency of FAAC specimens was greatly reduced. Further, alkali-activated fly ash has superior resistance to heat, as reported in the literature (Guerrieri and Sanjayan, 2010; Ranjbar et al., 2014; Rashad and Zeedan, 2011; Thokchom et al., 2012; Zhang et al., 2015). This could also have contributed to the much lower spalling frequency for the FAAC specimens, and is to be clarified in the following sections.

From Table 5 it also can be seen that, generally, the larger concrete specimens spalled more easily at high temperature. This could be because the thermal difference between inner and outer parts of the concrete is more pronounced for a larger specimen (Arioz, 2009).

After $1200^{\circ} \mathrm{C}$ treatment, photographs of the concrete specimens were taken and are shown in Figure 2. Although a larger quantity of NCC specimens spalled at high temperature (per Table 5), the extent of their spalling was not as severe as that of CLC specimens. This is probably because the initial strength of the latter was higher than that of the former. Nevertheless, during the heating, nearly all the FAAC specimens remained intact, without any clear damage.

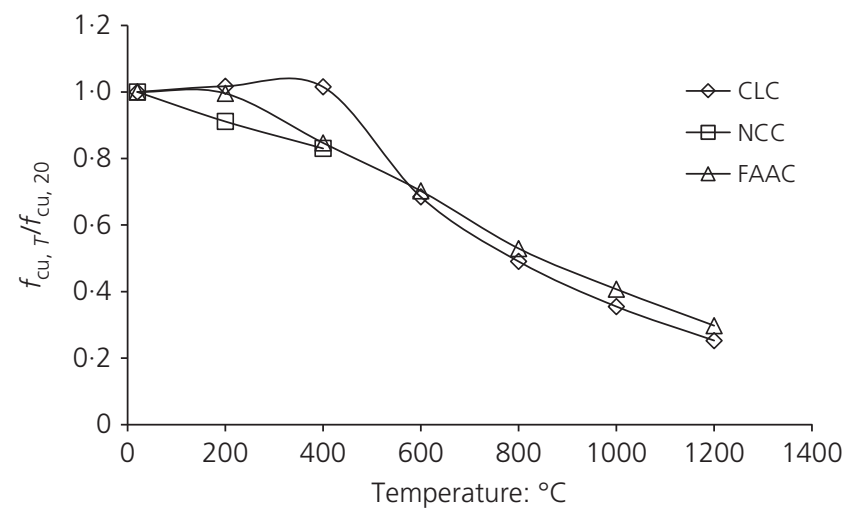

Figure 3. Relative $f_{\mathrm{cu}}$ of the concrete specimens after exposure to high temperatures

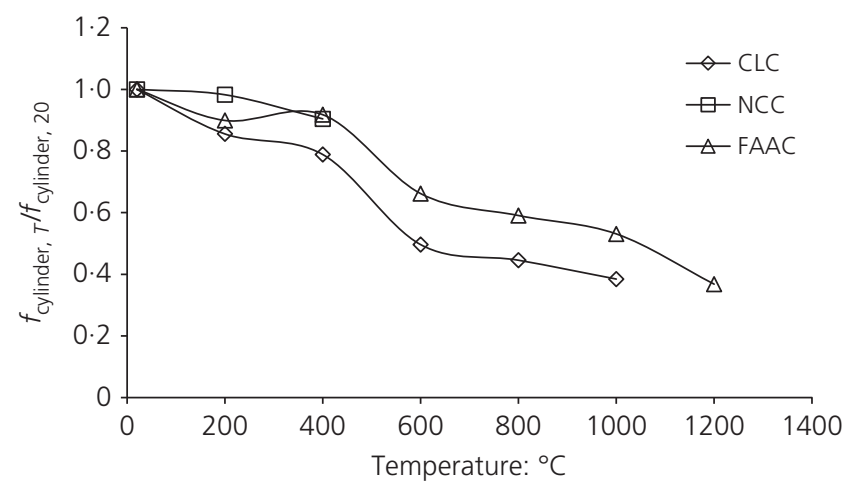

Figure 4. Relative $f_{\text {cylinder }}$ of the concrete specimens after exposure to high temperatures

\section{Residual mechanical properties}

\section{$f_{\text {cur }}, f_{\text {cylinder, }} f_{\mathrm{t}}, f_{\mathrm{f}}$ and $E$}

Relative values of $f_{\text {cu }}, f_{\text {cylinder }}, f_{\mathrm{t}}, f_{\mathrm{f}}$ and $E$ of the concrete specimens, which were calculated using their values at each temperature divided by their corresponding values at room temperature, are plotted in Figures 3 to 7, respectively. The data plotted are the average values of three specimens, except that spalled specimens were excluded, as they could not be used to provide values for calculation.

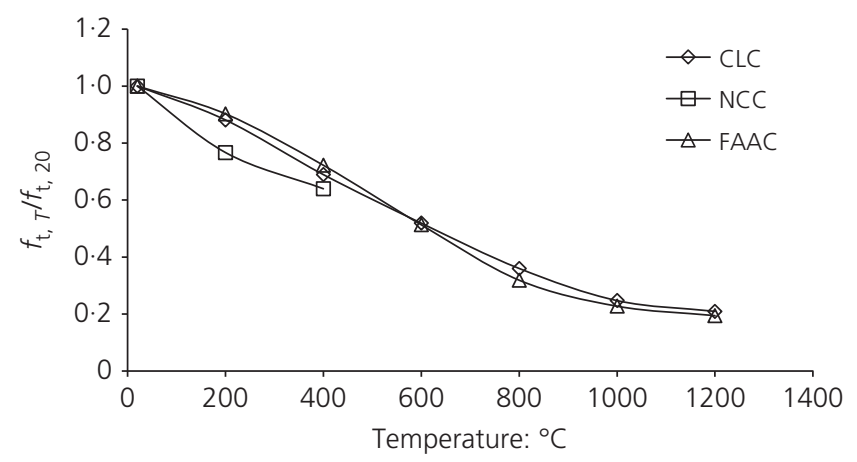

Figure 5. Relative $f_{\mathrm{t}}$ of the concrete specimens after exposure to high temperatures

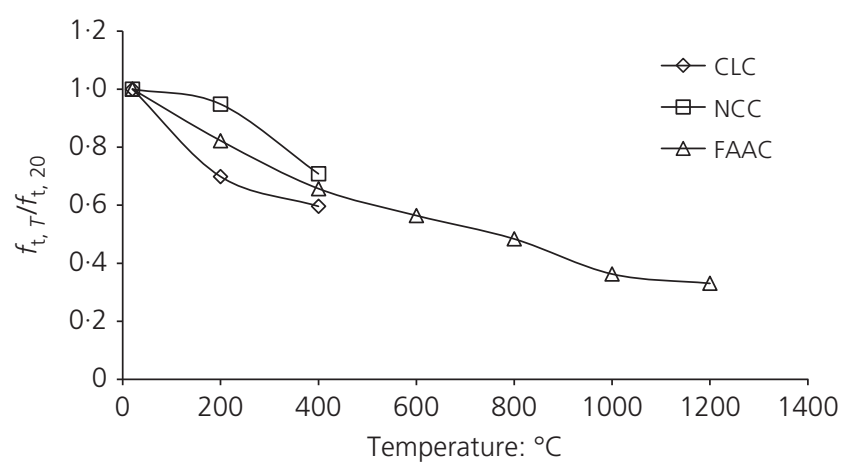

Figure 6. Relative $f_{\mathrm{f}}$ of the concrete specimens after exposure to high temperatures

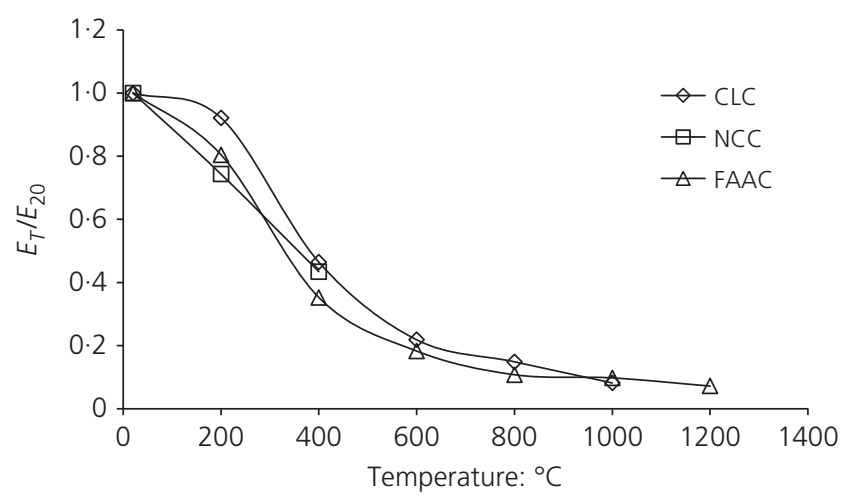

Figure 7. Relative $E$ of the concrete specimens after exposure to high temperatures 


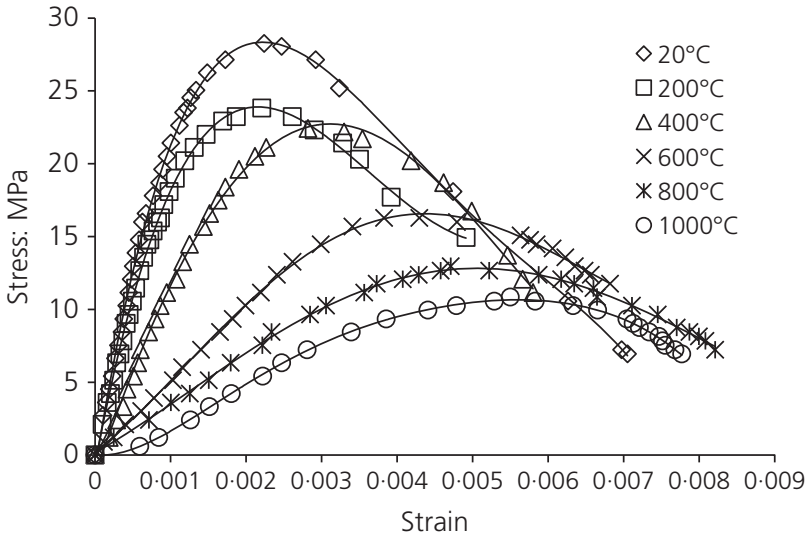

(a)

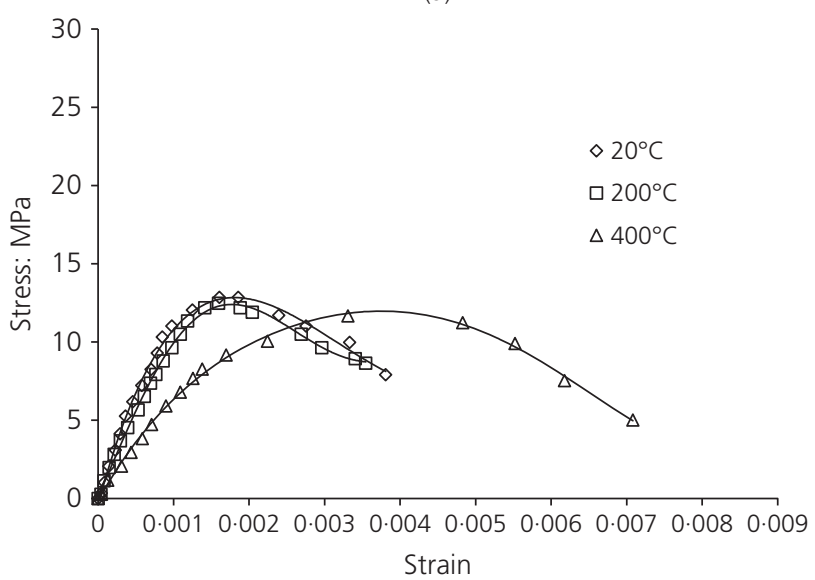

(b)

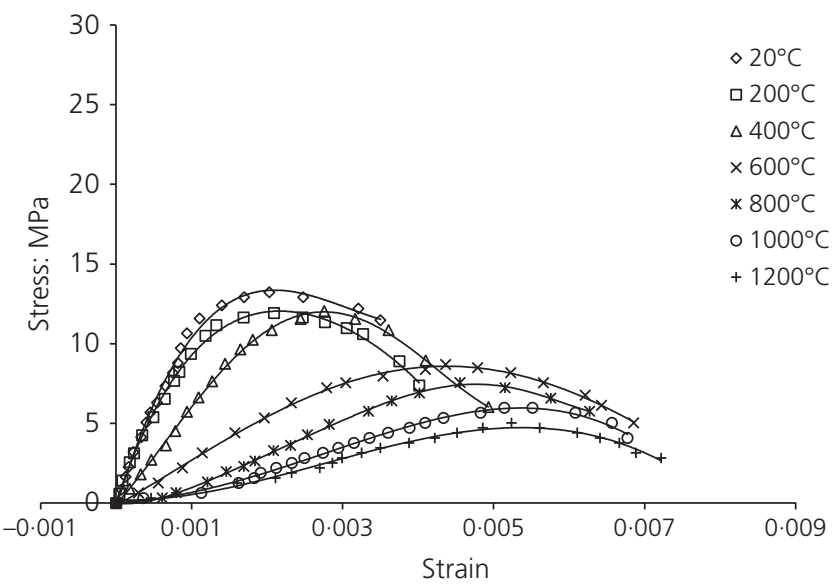

(c)

Figure 8. Stress-strain relationship of the concrete specimens after exposure to high temperatures: (a) CLC; (b) NCC; (c) FAAC

From the figures, it can be seen that after exposure to $1200^{\circ} \mathrm{C}$, the values of $f_{\text {cu }}, f_{\text {cylinder }} f_{\mathrm{t}}, f_{\mathrm{f}}$ and $E$ were $29 \cdot 8,36 \cdot 8,19 \cdot 4,33 \cdot 1$ and $7 \cdot 2 \%$ of the original values, respectively, for the FAAC specimens. However, none of the NCC specimens could survive when the temperature was as high as $600^{\circ} \mathrm{C}$. An extremely small number of CLC specimens remained intact after

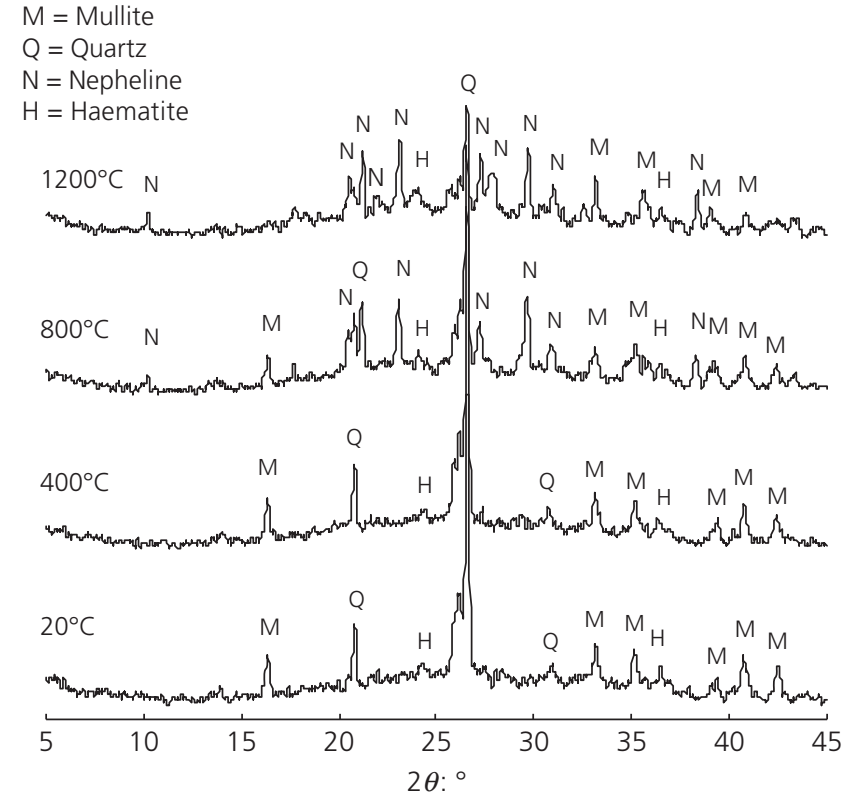

Figure 9. X-ray diffraction patterns of alkali-activated fly ash after exposure to different temperatures

$1200^{\circ} \mathrm{C}$, but their mechanical properties were generally not as good as those of the FAAC specimens. Therefore, it can be seen that once thermal spalling of lightweight aggregate concretes could be limited, they could behave very well even at a very high temperature.

\section{Stress-strain relationship}

Figure 8 plots the stress-strain relationship of the concrete specimens at room temperature and after heating. As with the strength results, the data plotted are average values obtained for those specimens that remained intact after heating.

From Figure 8 it can be seen that, with the increase in temperature, a flatter stress-strain curve was obtained for all the concrete specimens, indicating that their peak stress generally decreased with the increase in temperature. In addition, the peak stress shifted rightwards as temperature increased, which illustrates the increase of the corresponding strain.

Compared with the CLC specimens, the peak stress of both the NCC and the FAAC specimens was fairly lower, both at room temperature and after exposure to the high temperatures. However the corresponding strain was similar for the different concrete mixes. This indicates that, during the whole temperature evolution, the NCC and the FAAC specimens had a better elastic deformation than the CLC specimen.

\section{X-ray diffraction of alkali-activated fly ash}

To explore the chemical changes of alkali-activated fly ash with increasing temperature, X-ray diffraction analysis was 


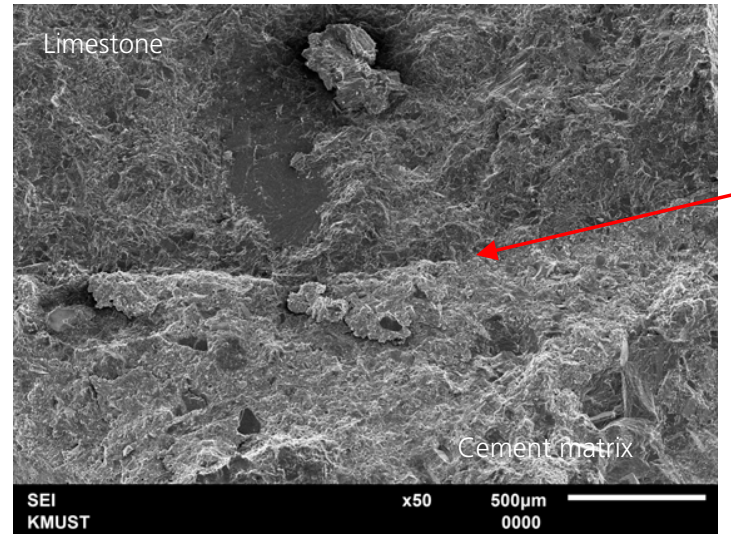

(a)

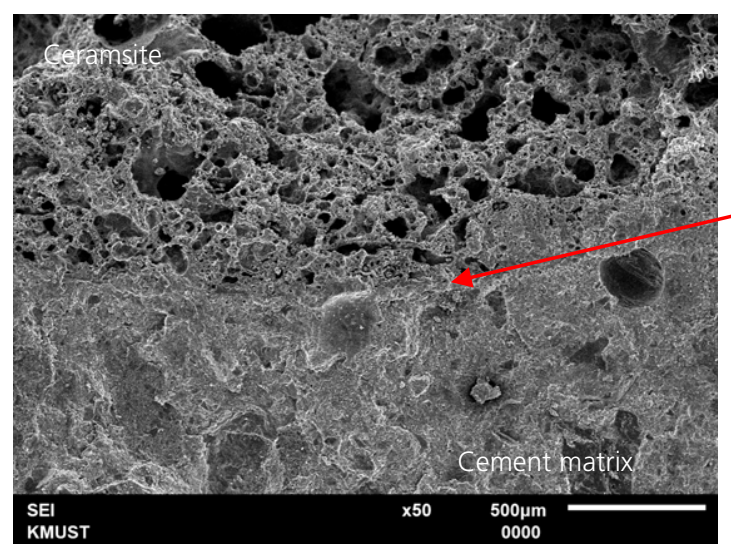

(c)

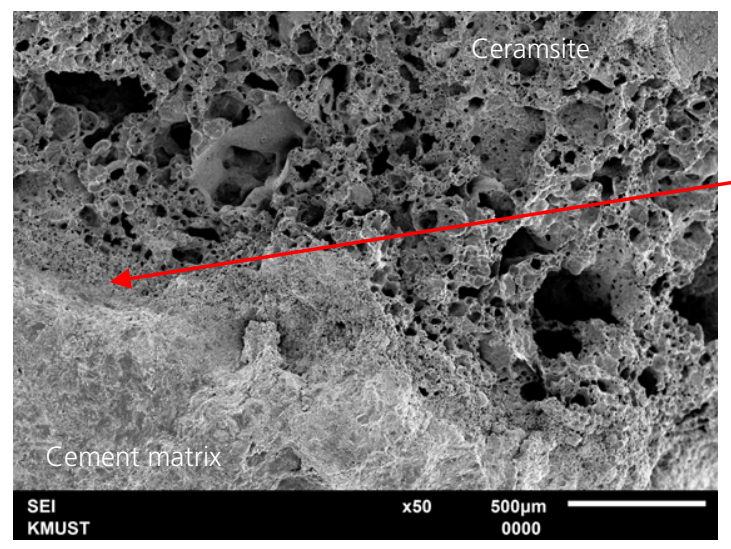

(e)

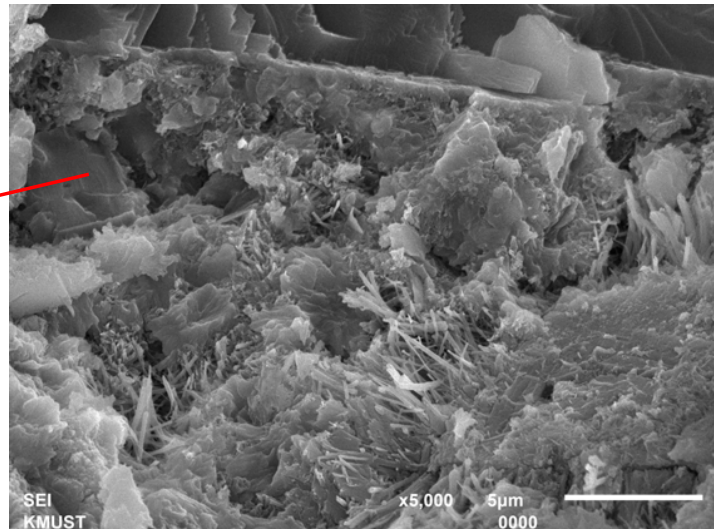

(b)

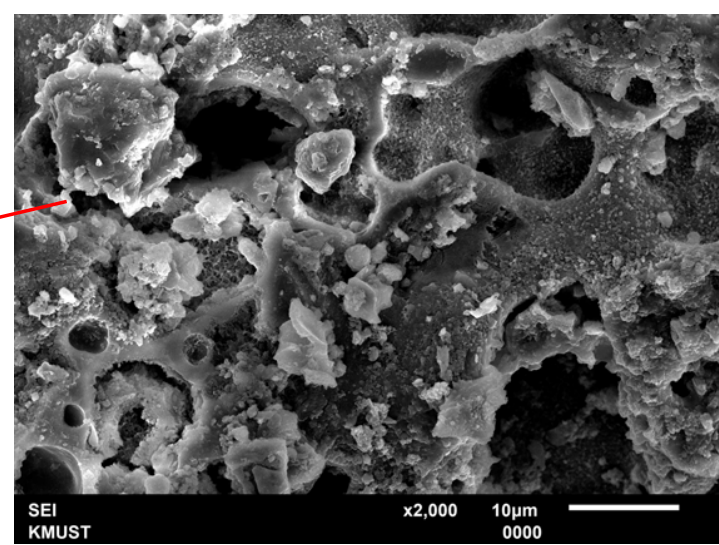

(d)

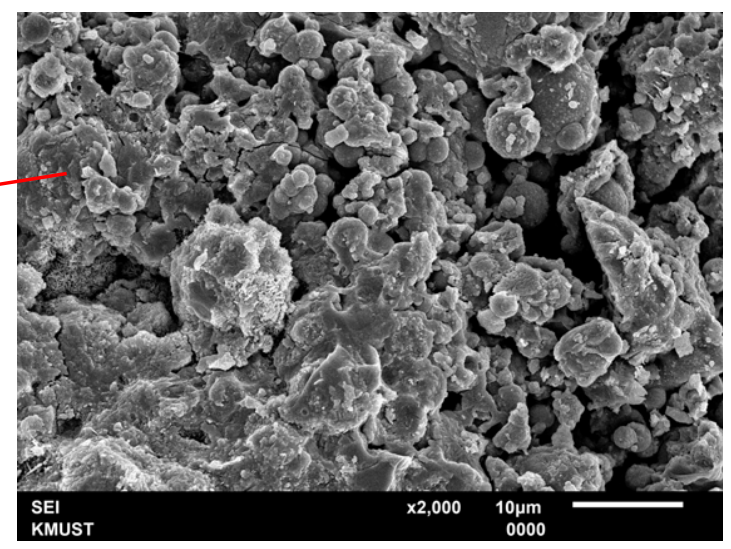

(f)

Figure 10. Scanning electron micrographs of the concretes at room temperature: (a) CLC; (b) interfacial transition zone of CLC; (c) NCC; (d) interfacial transition zone of NCC; (e) FAAC; (f) alkali-activated fly ash

conducted of the alkali-activated fly ash paste samples at room temperature and after exposure to $400^{\circ} \mathrm{C}, 800^{\circ} \mathrm{C}$ and $1200^{\circ} \mathrm{C}$, respectively; the patterns at each temperature are shown in Figure 9.

From Figure 9, it can be seen that, at room temperature, the main chemicals of the alkali-activated fly ash were quartz
$\left(\mathrm{SiO}_{2}\right)$ and mullite (aluminium silicate), as well as a small amount of haematite. These chemicals were considered to originate from the fly ash (Rashad and Zeedan, 2011); this indicates that the fly ash has not yet been well activated. Similar chemicals were still observed when the temperature increased to $400^{\circ} \mathrm{C}$. This could also be a result of an insufficient activation. After $800^{\circ} \mathrm{C}$, nepheline $\left(\mathrm{NaAlSiO}_{4}\right)$ was formed in the 


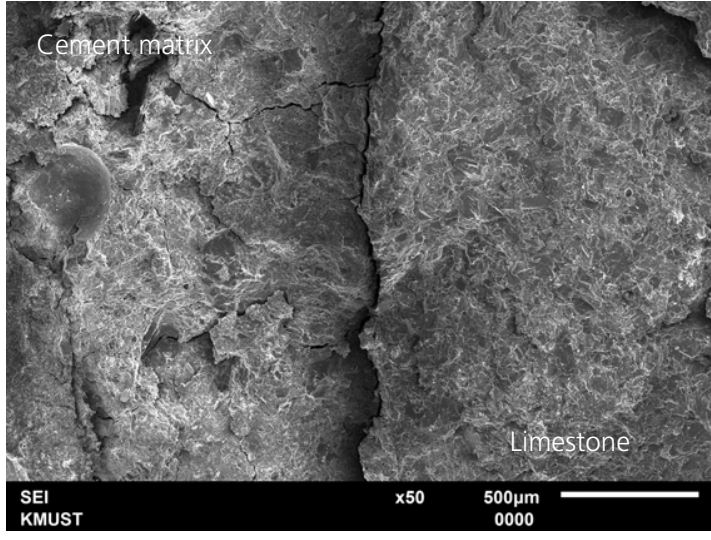

(a)

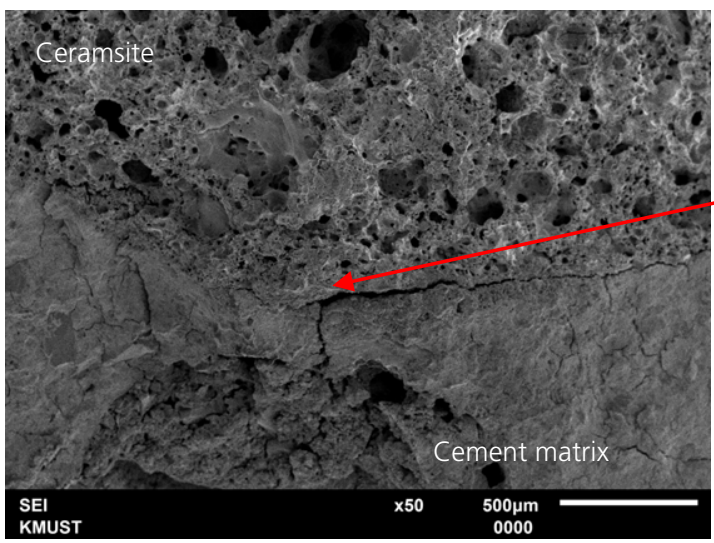

(c)

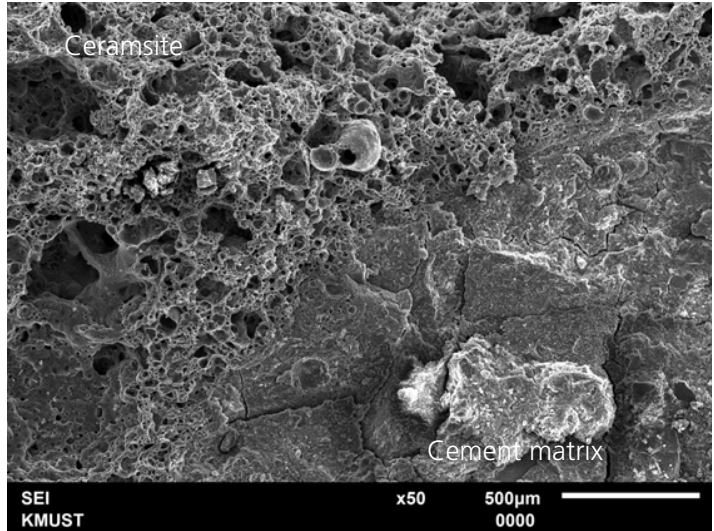

(b)

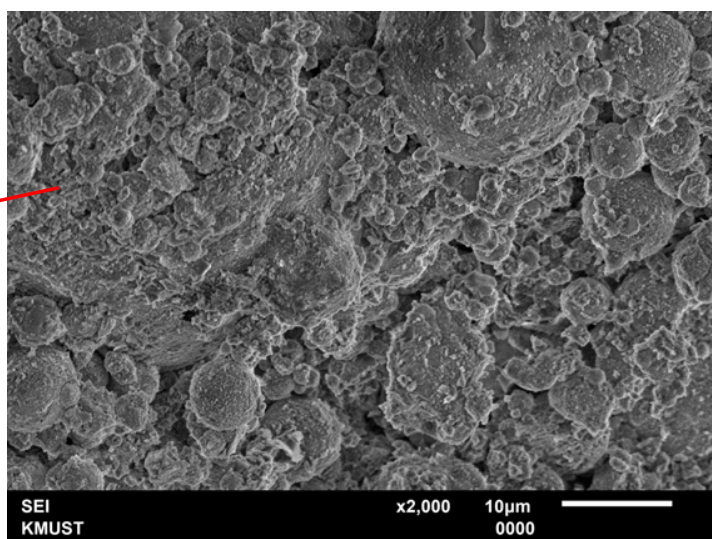

(d)

Figure 11. Scanning electron micrographs of the concretes after exposure to $400^{\circ} \mathrm{C}$ : (a) CLC; (b) NCC; (c) FAAC; (d) alkali-activated fly ash

system. Other researchers also found similar hydrates for alkali-activated fly ash at room temperature and after exposure to high temperatures (Ranjbar et al., 2014; Rashad and Zeedan, 2011; Thokchom et al., 2012; Zhang et al., 2015).

From Table 5, it is known that the NCC specimens usually spalled around $400^{\circ} \mathrm{C}$. However, from this discussion, it can be seen that the fly ash in the FAAC specimens has not been well activated at this temperature. As a result, the structure of the alkali-activated fly ash coating was not dense enough, as shown in Figures 10 and 11, which is to be discussed later. Such a coating could have merely provided channels for the vapour in the ceramsites to escape, reducing the possibility of spalling. Afterwards, the formation of nepheline in this kind of thermally stable mineral could have made the coating denser (Rashad and Zeedan, 2011; Zhang et al., 2015), strengthening the ceramsites to resist further heating.

\section{Microscopic structure}

Figures 10 to 12 show scanning electron micrographs of the concrete specimens at room temperature and after exposures to $400^{\circ} \mathrm{C}$ and $1200^{\circ} \mathrm{C}$, respectively.
From Figure 10 it can be seen that, at room temperature, crystalline phases in the CLC specimen orientated in the interfacial transition zone between the cement matrix and the limestone. Cement and alkali-activated fly ash have filled the surface pores of the ceramsite particles for the NCC and the FAAC specimens, respectively. However, probably because the fly ash has not been activated well at room temperature, the microscopic structure of the alkali activated fly ash coating was not sufficiently dense.

After heating to $400^{\circ} \mathrm{C}$, probably owing to the inconsistency of deformation between the cement matrix and the limestone (Ma et al., 2015), cracks were clearly observed in the interfacial transition zone of the CLC specimen. Ceramsite is much weaker than limestone. The cement that filled in the surface pores of the ceramsite particles could have connected the cement matrix and the ceramsite particles in the NCC specimen, so that there was not a clear boundary between the two. Probably owing to this good connection, it was difficult for vapour in the ceramsite particles to escape through the strengthened surface, resulting in the spalling of the concrete, as reported in Table 5. The fly ash in the FAAC specimen has 


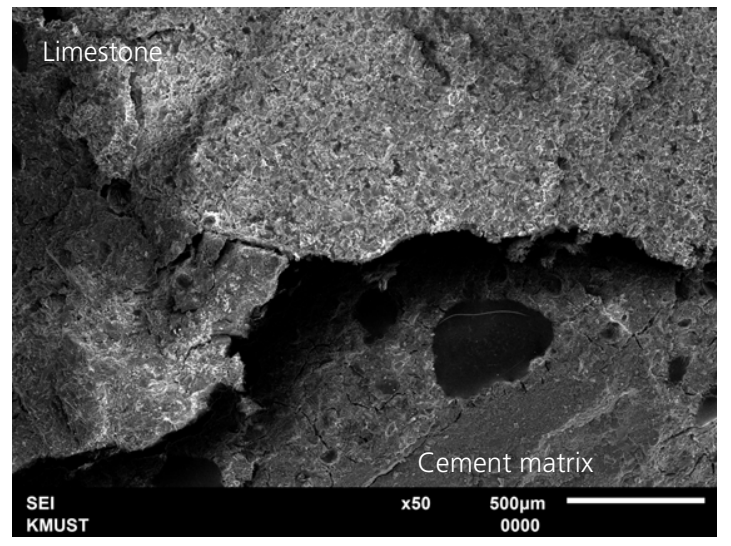

(a)

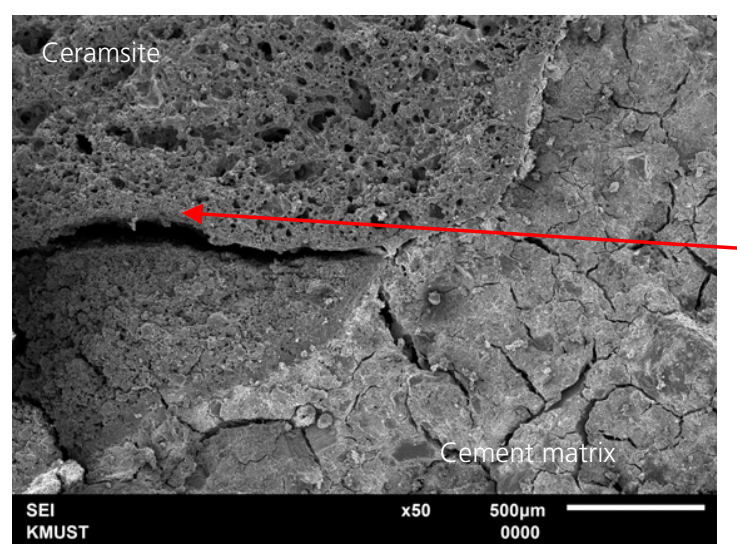

(c)

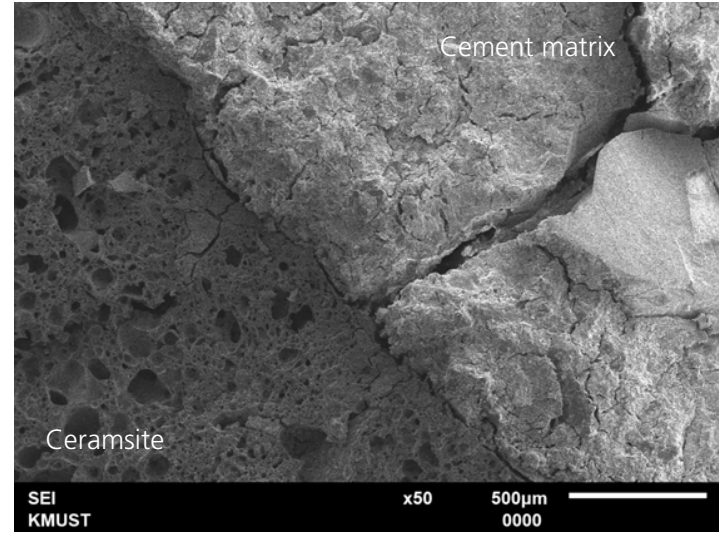

(b)

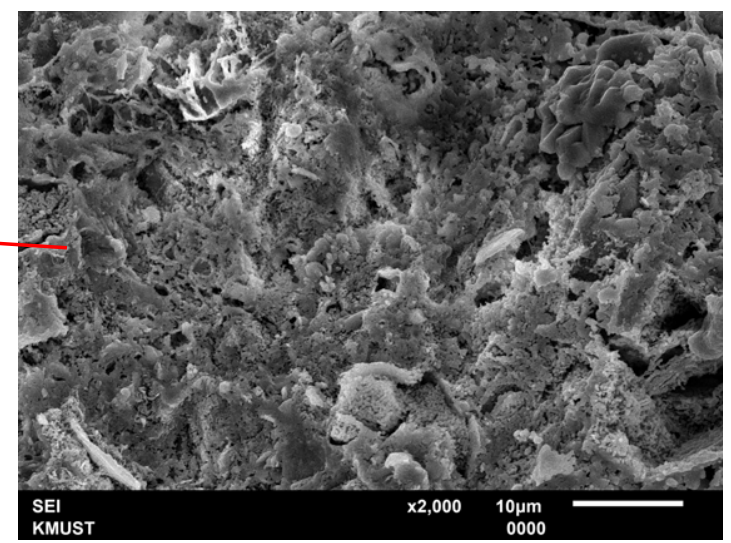

(d)

Figure 12. Scanning electron micrographs of the concretes after exposure to $1200^{\circ} \mathrm{C}$ : (a) CLC; (b) NCC; (c) FAAC; (d) alkali-activated fly ash

not been well activated, even at $400^{\circ} \mathrm{C}$, as discussed previously. As a result, from the scanning electron micrograph, it can be seen that the microscopic structure of the alkali-activated fly ash coating was not dense enough, and clear cracks appeared in the interfacial transition zone. However, such a loose structure and cracks might have provided channels for the vapour in the ceramsite particles to escape, reducing the possibility of spalling of the FAAC specimens.

With an increase in temperature to $1200^{\circ} \mathrm{C}$, the cracks in the interfacial transition zone of the CLC specimen enlarged further. However, the cracks originating in the cement matrix of the NCC specimen extended into the inner volume of the ceramsite particles because ceramsite is not as strong as limestone. The fly ash in the FAAC specimen has obtained an improved activation after heating to $800^{\circ} \mathrm{C}$, as discussed previously. As a result, the alkali-activated fly ash coating could have protected the ceramsite particles against the penetration of cracks from the cement matrix to the inner volume of the particles. Instead, the cracks in the FAAC specimen developed along the interfacial transition zone, but to a smaller extent than those in the CLC specimen.

\section{In situ macroscopic structure}

In situ images of the concrete specimens at room temperature, $400^{\circ} \mathrm{C}, 600^{\circ} \mathrm{C}$ and $800^{\circ} \mathrm{C}$ were collected, respectively, as shown in Figure 13. Because the specimens were sufficiently small and images of section surfaces were taken, spalling could not occur for all the specimens. In this context, the purpose of this test was only to demonstrate the cracking modes of the different concrete specimens, where thermal spalling was not considered. The cracks induced by heating are marked on the images using red lines.

As shown in Figure 13, fine cracks were first observed in the cement matrix of the CLC specimen when the temperature raised to around $400^{\circ} \mathrm{C}$. With further increases of temperature, to $600^{\circ} \mathrm{C}$ and $800^{\circ} \mathrm{C}$, the cracks in the cement matrix extended through sand particles and developed further, along the edge of the limestone particles. It should be noted here that the cracks in the limestone particle (the one on the right bottom) had been there at room temperature and, therefore, could be ignored in the discussion although they expanded further with increasing temperature. For the NCC specimen, when the temperature was below $600^{\circ} \mathrm{C}$, the cracks in the specimen were 

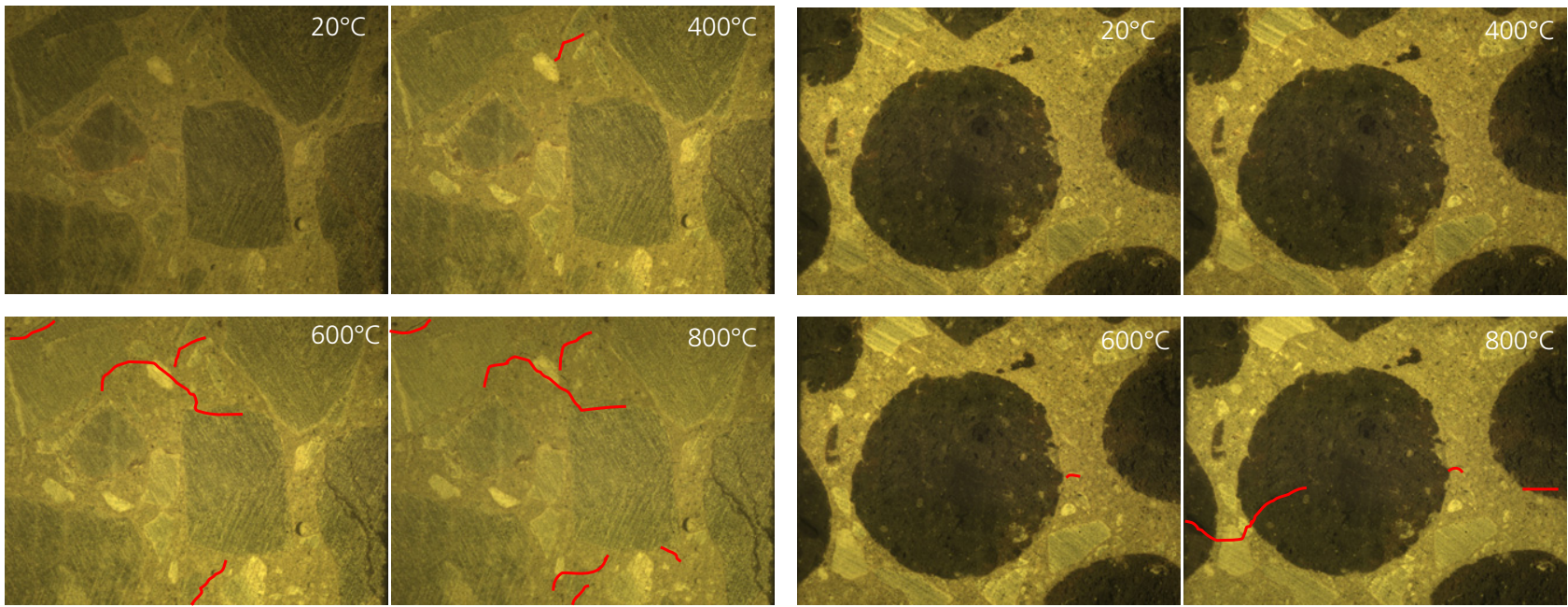

(a)

(b)
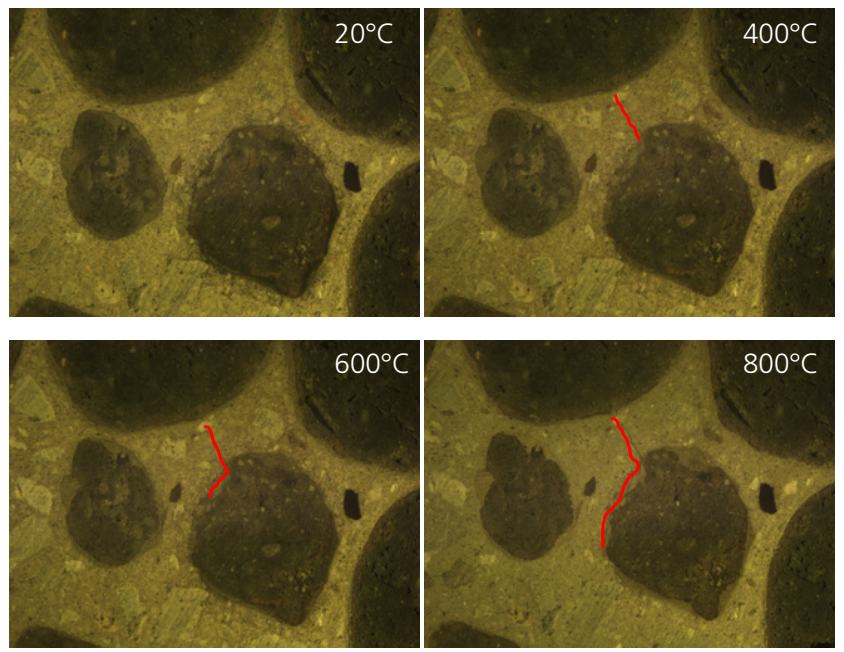

(c)

Figure 13. In situ images of the concrete specimens at the different temperatures: (a) CLC; (b) NCC; (c) FAAC

not clearly seen. After that, cracks started to appear in the cement matrix and then penetrated through the ceramsite particles when the temperature was increased to $800^{\circ} \mathrm{C}$. Owing to the strengthening of alkali-activated fly ash at high temperature, the cracks originating in the cement matrix of the FAAC specimen did not penetrate through the ceramsites, but extended along the edge of the ceramsite particles instead.

\section{Conclusions}

Based on the materials and the test procedures used in this paper, the following results were found.

- The use of alkali-activated fly ash to precoat ceramsites extremely reduced the spalling possibility of the ceramsite concretes.
- After exposure to $1200^{\circ} \mathrm{C}$, the FAAC specimens still had $\operatorname{good} f_{\text {cu }}, f_{\text {cylinder }}, f_{\mathrm{t}}, f_{\mathrm{f}}$ and $E$.

- With the increase in temperature, the peak stress of the FAAC specimens reduced and the corresponding strain increased; this behaviour was similar to that of the CLC and NCC specimens.

- After exposure to $800^{\circ} \mathrm{C}$, nepheline was formed in the hydrates of alkali-activated fly ash. The formation of this thermally stable phase could greatly improve the performance of such a system at high temperature.

- Heat-induced cracks appeared first in the cement matrix of the CLC specimen and then extended along the edge of the limestone particles. However, cracks in the NCC specimen could penetrate through the ceramsite particles. Alkali-activated fly ash protected the ceramsite particles in the FAAC specimen against cracking penetration; cracks in 
the concrete evolved in a similar way as those developing in the CLC specimen.

\section{Acknowledgements}

This project is supported by the National Natural Science Foundation of China (grant numbers 51502121 and 11562010), the China Postdoctoral Science Foundation (postdoctorate number 150039; grant number 2015M572646XB) and the Foundation for the Introduction of Talent of Kunming University of Science and Technology (grant number KKSY201406112). All of these are gratefully acknowledged.

\section{REFERENCES}

Arioz O (2009) Retained properties of concrete exposed to high temperatures: size effect. Fire and Materials 33(5): 211-222.

Bideci OS (2016) The effect of high temperature on lightweight concretes produced with colemanite coated pumice aggregates. Construction and Building Materials 113: 631-640.

Choi WC, Kim SW, Jang SJ and Yun HD (2017) Research trends and design guidelines for fire resistance of structural concrete in South Korea. Magazine of Concrete Research 69(7): 347-364, https://doi.org/10.1680/jmacr.15.00361.

Consolazio GR, McVay MC and Rish JW, III (1998) Measurement and prediction of pore pressures in saturated cement mortar subjected to radiant heating. ACI Material Journal 95(5): 525-536.

Gao WY, Dai JG and Teng JG (2017) Fire resistance of RC beams under design fire exposure. Magazine of Concrete Research 69(8): 402-423, https://doi.org/10.1680/jmacr.15.00329.

Guerrieri M and Sanjayan JG (2010) Behavior of combined fly ash/slag-based geopolymers when exposed to high temperatures. Fire and Materials 34(4): 163-175.

Guo R, Ma Q, Sun Y et al. (2016) A Method to Coat Lightweight Aggregates and the Application of the Lightweight Aggregates After the Coating. Chinese Patent 2014107306978, Aug.

Jiang Y, Huo D, Teng H and Qiao Y (2013) Study on performance of shale ceramsite concrete after exposure to high temperature. Journal of Building Materials 16(5): 888-892 (in Chinese).

Leca (2017) Leca: Light Expanded Clay Aggregate. See http://www.leca. ae (accessed 31/12/2017)

Lindgard J and Hammer TA (1998) Fire resistance of structural lightweight aggregate concrete: a literature survey with focus on spalling. Nordic Concrete Research 21: 14-25.

Lytag (2017) Lytag: Lightweight Solutions. See http://www.lytag.com (accessed 31/12/2017).

Ma Q, Guo R, Zhao Z, Lin Z and He K (2015) Mechanical properties of concrete at high temperature - a review. Construction and Building Material 93: 371-383.
Ma Q, Guo R, Sun Y et al. (2018) Behaviour of modified lightweight aggregate concrete after exposure to elevated temperatures. Magazine of Concrete Research 70(5): 217-230, https://doi.org/ 10.1680/jmacr.17.00136.

Ranjbar N, Mehrali M, Alengaram UJ, Metselaar HSC and Jumaat MZ (2014) Compressive strength and microstructural analysis of fly ash/palm oil fuel ash based geopolymer mortar under elevated temperatures. Construction and Building Materials $\mathbf{6 5}$ 114-121.

Rashad AM and Zeedan SR (2011) The effect of activator concentration on the residual strength of alkali-activated fly ash pastes subjected to thermal load. Construction and Building Materials 25(7): 3098-3107.

SAC (Standardisation Administration of China) (2002a) JGJ 51-2002: Technical specification for lightweight aggregate concrete. Ministry of Housing and Urban-Rural Development, Beijing, People's Republic of China.

SAC (2002b) GB/T 50080-2002: Standard for test method of performance on ordinary fresh concrete. Ministry of Housing and Urban-Rural Development, Beijing, People's Republic of China.

SAC (2002c) GB/T 50081-2002: Standard for test method of mechanical properties on ordinary concrete. Ministry of Housing and Urban-Rural Development, Beijing, People's Republic of China.

SAC (2007) GB 175-2007: Common Portland cement. General Administration of Quality Supervision, Inspection and Quarantine, Beijing, People's Republic of China.

SAC (2011) JGJ 55-2011: Specification for mix proportion design of ordinary concrete. Ministry of Housing and Urban-Rural Development, Beijing, People's Republic of China.

Sancak E, Sari YD and Simsek O (2008) Effects of elevated temperature on compressive strength and weight loss of the light-weight concrete with silica fume and superplasticizer. Cement and Concrete Composites 30(8): 715-721.

Tanyildizi $\mathrm{H}$ and Coskun A (2008) Performance of lightweight concrete with silica fume after high temperature. Construction and Building Materials 22(10): 2124-2129.

Thokchom S, Mandal KK and Ghosh S (2012) Effect of Si/Al ratio on performance of fly ash geopolymers at elevated temperature. Arab Journal of Science Engineering 37(4): 977-989.

Turkmen I and Findik SB (2013) Several properties of mineral admixtured lightweight mortars at elevated temperatures. Fire and Materials 37(5): 337-349.

Yoon M, Kim G, Choe GC, Lee Y and Lee T (2015) Effect of coarse aggregate type and loading level on the high temperature properties of concrete. Construction and Building Materials 78: 26-33.

Zhang Z, Provis JL, Reid A and Wang H (2015) Mechanical, thermal insulation, thermal resistance and acoustic absorption properties of geopolymer foam concrete. Cement and Concrete Composites 62: $97-105$

\section{How can you contribute?}

To discuss this paper, please submit up to 500 words to the editor at journals@ice.org.uk. Your contribution will be forwarded to the author(s) for a reply and, if considered appropriate by the editorial board, it will be published as a discussion in a future issue of the journal. 